\title{
Scenario Development at the Vertical Motion Simulator
}

\author{
Scott E. Reardon ${ }^{1}$ and Steven D. Beard. ${ }^{2}$ \\ NASA Ames Research Center, Moffett Field, CA, 94035 \\ Emily Lewis ${ }^{3}$ \\ SAIC, NASA Ames Research Center, Moffett Field, CA, 94035
}

\begin{abstract}
There has been a significant effort within the simulation community to standardize many aspects of flight simulation. More recently, an effort has begun to develop a formal scenario definition language for aviation. A working group within the AIAA Modeling and Simulation Technical Committee has been created to develop a standard aviation scenario definition language, though much of the initial effort has been tailored to training simulators. Research and development (R\&D) simulators, like the Vertical Motion Simulator (VMS), and training simulators have different missions and thus have different scenario requirements. The purpose of this paper is to highlight some of the unique tasks and scenario elements used at the VMS so they may be captured by scenario standardization efforts. The VMS most often performs handling qualities studies and transfer of training studies. Three representative handling qualities simulation studies and two transfer of training simulation studies are described in this paper. Unique scenario elements discussed in this paper included special out-the-window (OTW) targets and environmental conditions, motion system parameters, active inceptor parameters, and configurable vehicle math model parameters.
\end{abstract}

\section{Introduction}

$\mathrm{G}$ round based flight simulation is used extensively by industry and the military as a cost effective means of training Jilots. Though most flight simulators have similar components and subsystems, the underlying architecture can be significantly different thus making it difficult to share resources between simulation facilities. There has been a substantial effort within the simulation community to standardize many aspects of flight simulation, though much of the effort has been tailored to training simulators.

In the 1990s the AIAA Modeling and Simulation Technical Committee began development on a standard format for the exchange of flight dynamics models ${ }^{1}$ which would facilitate the exchange of vehicle math models between simulation facilities. The ANSI/AIAA Flight Dynamics Model Exchange Standard ${ }^{2}$ was approved in March of 2011. In the mid 2000s an effort to develop objective simulator motion criteria was initiated with the goal of eliminating subjective judgement to validate simulator motion. ${ }^{3}$ As a result, the International Civil Aviation Organization (ICAO) Objective Motion Cueing Test (OMCT) was developed under the guidance of the Royal Aeronautical Society. ${ }^{4}$ More recently, an effort has begun to develop a formal scenario definition language for aviation. ${ }^{5}$ A working group within the AIAA Modeling and Simulation Technical Committee has been created to develop a standard aviation scenario definition language.

Research and development $(R \& D)$ simulators and training simulators have different missions and thus have different scenario requiremens. R\&D simulator are most commonly used to learn about the combined pilot-vehicle interactions using flight scenarios that focus on a specific area of interest. The purpose of this paper is to highlight some of the unique scenario elements that may be common to a research and development simulator, such as the Vertical Motion Simulator (VMS), so they may be captured by scenario standardization efforts.

\section{Background}

\section{A. Vertical Motion Simulator Description}

For nearly 40 years of continuous operation, the Vertical Motion Simulator has contributed significantly to the body of knowledge in a range of disciplines including human pilot cueing modalities and simulation fidelity, vehicle

\footnotetext{
${ }^{1}$ VMS Laboratory Manager, Aerospace Simulation Research and Development Branch, MS 243-5, Member.

${ }^{2}$ Chief, Aerospace Simulation Research and Development Branch, MS 243-1, Senior Member.

3 Senior Simulation Engineer, NASA ARC SimLabs, Mail Stop 243-6, Member.
}

American Institute of Aeronautics and Astronautics 
handling qualities (HQ) and flight control design, and pilotvehicle interface design. ${ }^{6}$ The VMS has been primarily used as an R\&D simulator, though has been used for combination of training and engineering studies during the Shuttle program. ${ }^{7}$

The VMS, shown in Fig. 1, is an uncoupled, six-degreeof-freedom motion simulator that moves within the confines of a hollow ten-story building. The VMS motion capabilities are provided in Table 1. Included in the table are two sets of limits: system limits that represent the absolute maximum level attainable under controlled conditions; and operational limits that represent attainable levels for normal piloted operations. $^{8}$

The VMS has five interchangeable cabs (ICABs), each having a different out-the-window (OTW) visual field-ofview (FOV), that is representative of a class of vehicle. The ICABs can be customized for an experiment by installing various flight controls, instruments, instrument panels, displays and seats to meet research requirements.

A Rockwell-Collins EPX5000 computer image generator creates the OTW visual scene. Flight instrumentation and other vehicle information are provided on head-down displays that are generated using separate graphic processors. The OTW and head-down display graphics are created in-house and are usually customized for each experiment. ${ }^{9}$

The flight controls are heavily modified and optimized McFadden hydraulic force-loader systems with a custom digital-control interface. The custom digital-control interface allows for comprehensive adjustment of the controller's static and dynamic characteristics. A variety of vehicle manipulators, ranging from the regular column-and-wheel type to conventional rotorcraft controls and side sticks may be combined with the force-loader systems. ${ }^{10}$

Table 1. VMS motion system performance limits.

\begin{tabular}{|c|c|c|c|c|c|c|}
\hline \multirow{2}{*}{$\begin{array}{l}\text { Degree } \\
\text { of } \\
\text { Freedom }\end{array}$} & \multicolumn{2}{|c|}{ Displacement } & \multicolumn{2}{|c|}{ Velocity } & \multicolumn{2}{|c|}{ Acceleration } \\
\hline & $\begin{array}{l}\text { System } \\
\text { Limits }\end{array}$ & $\begin{array}{l}\text { Operational } \\
\text { Limits }\end{array}$ & $\begin{array}{l}\text { System } \\
\text { Limits }\end{array}$ & $\begin{array}{l}\text { Operational } \\
\text { Limits }\end{array}$ & $\begin{array}{l}\text { System } \\
\text { Limits }\end{array}$ & $\begin{array}{l}\text { Operational } \\
\text { Limits }\end{array}$ \\
\hline Longitudinal & $\pm 4 \mathrm{ft}$ & $\pm 3 \mathrm{ft}$ & $\pm 5 \mathrm{ft} / \mathrm{sec}$ & $\pm 4 \mathrm{ft} / \mathrm{sec}$ & $\pm 16 \mathrm{ft} / \mathrm{sec}^{2}$ & $\pm 10 \mathrm{ft} / \mathrm{sec}^{2}$ \\
\hline Lateral & $\pm 20 \mathrm{ft}$ & $\pm 15 \mathrm{ft}$ & $\pm 8 \mathrm{ft} / \mathrm{sec}$ & $\pm 8 \mathrm{ft} / \mathrm{sec}$ & $\pm 13 \mathrm{ft} / \mathrm{sec}^{2}$ & $\pm 13 \mathrm{ft} / \mathrm{sec}^{2}$ \\
\hline Vertical & $\pm 30 \mathrm{ft}$ & $\pm 22 \mathrm{ft}$ & $\pm 16 \mathrm{ft} / \mathrm{sec}$ & $\pm 15 \mathrm{ft} / \mathrm{sec}$ & $\pm 22 \mathrm{ft} / \mathrm{sec}^{2}$ & $\pm 22 \mathrm{ft} / \mathrm{sec}^{2}$ \\
\hline Roll & $\pm 0.31 \mathrm{ft}$ & $\pm 0.24 \mathrm{rad}$ & $\pm 0.9 \mathrm{rad} / \mathrm{sec}$ & $\pm 0.7 \mathrm{rad} / \mathrm{sec}$ & $\pm 4 \mathrm{rad} / \mathrm{sec}^{2}$ & $\pm 2 \mathrm{rad} / \mathrm{sec}^{2}$ \\
\hline Pitch & $\pm 0.31 \mathrm{ft}$ & $\pm 0.24 \mathrm{rad}$ & $\pm 0.9 \mathrm{rad} / \mathrm{sec}$ & $\pm 0.7 \mathrm{rad} / \mathrm{sec}$ & $\pm 4 \mathrm{rad} / \mathrm{sec}^{2}$ & $\pm 2 \mathrm{rad} / \mathrm{sec}^{2}$ \\
\hline Yaw & $\pm 0.42 \mathrm{ft}$ & $\pm 0.34 \mathrm{rad}$ & $\pm 0.9 \mathrm{rad} / \mathrm{sec}$ & $\pm 0.8 \mathrm{rad} / \mathrm{sec}$ & $\pm 4 \mathrm{rad} / \mathrm{sec}^{2}$ & $\pm 2 \mathrm{rad} / \mathrm{sec}^{2}$ \\
\hline
\end{tabular}

\section{B. Scenario Overview}

Many actual and conceptual vehicles have been simulated at the VMS, including various helicopters, Vertical/Short Take-Off and Landing and Conventional aircraft, tilt-rotors, airships, spacecraft, and the Space Shuttle. Similarly, a wide variety of research topics have been studied at the VMS. The evaluation maneuvers flown during these experiments have ranged from very realistic, full mission tasks used for workload or certification studies to semirealistic mission elements used for HQ, proof-of-concept studies, specialized tracking tasks required for transfer of training, and motion cueing fidelity studies. Some examples of common VMS tasks are shown below.

\section{Sample $H Q$ Tasks}

American Institute of Aeronautics and Astronautics 
1) In 2016 an experiment was performed in the VMS for the FAA with the purpose of defining HQ requirements for advanced civilian rotorcraft. The pilots were asked to fly full mission and high workload tasks using a helicopter math model with five different advanced flight control systems and an autopilot. These scenarios required pilots to fly in IFR conditions with turbulence, approach profiles into a dozen different airports with air traffic control communication, using emulated legacy flight instruments (left seat) and real flight avionic (right seat). Figure 2 below shows a picture of the cab interior in a departure initial condition.

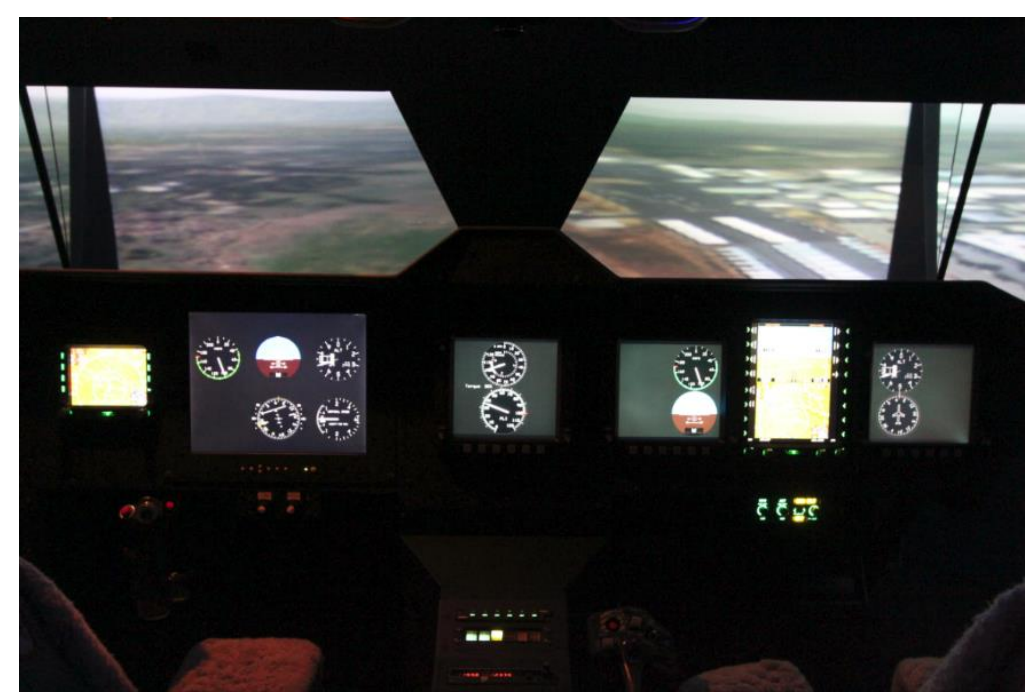

Figure 2. Advanced rotorcraft cab interior for full-mission scenarios.

2) The U. S. Army Aeroflightdynamics Directorate (AFDD), in collaboration with NASA Ames Research Center, began an effort to build a database of HQ data and design criteria that could be incorporated into a new HQ specification. The strategy for developing a helicopter HQ database of sufficient quality and validity for use in a military specification was to combine high-fidelity simulation with a limited amount of flight test activity. Almost all the simulation data incorporated into ADS-33 came from VMS studies. The existing specification, US Army Aeronautical Design Standard - 33 or ADS-33, was completed and published in 1987. ${ }^{11}{ }^{12}$ Since 1987 , the VMS has performed many HQ experiment used to update ADS-33 design standards. The ADS-33 scenarios, also known as Mission Task Elements (MTE), requires accurately sized and

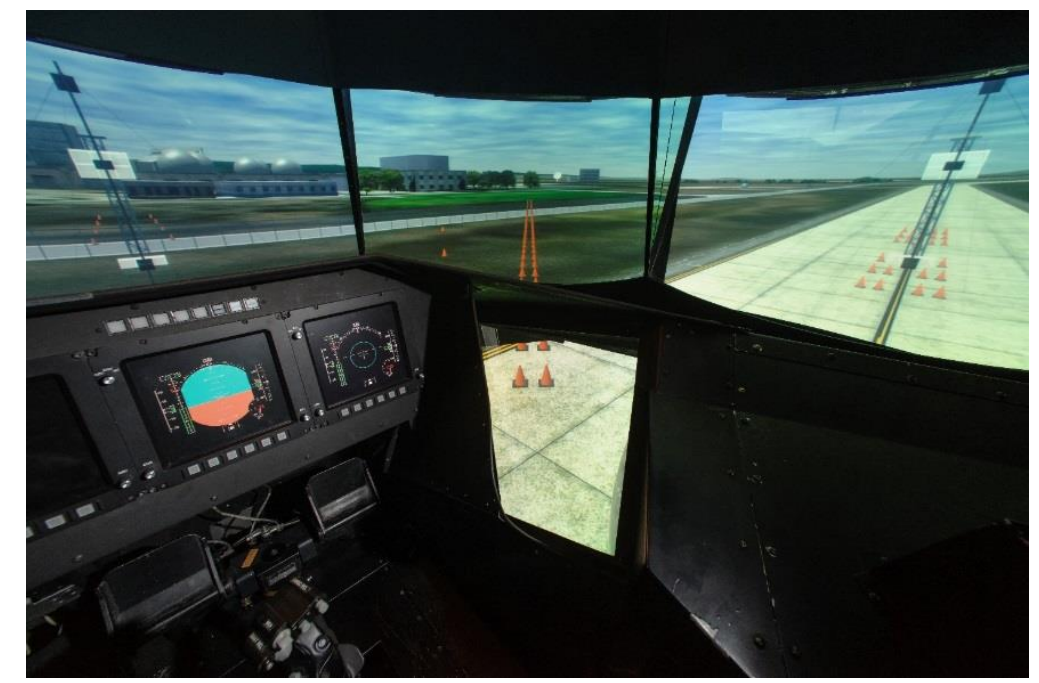

Figure 3. Cab interior for hover scenario. 
positioned visual cueing targets in the OTW scene. Figure 3 shows the OTW view from the pilot's point of view for the Hover MTE.

3) In 2013, NASA and the U.S. Army jointly conducted a simulation experiment in the VMS that examined and quantified the effects of limited-authority control system augmentation on HQ and task performance in both good and degraded visual environments. Evaluation tasks included the ADS-33 Hover, Sidestep, Acceleration/Deceleration, and Pirouette Mission Task Elements, as well as a new proposed Emergency Medical Services task that includes an approach and landing at a minimally prepared remote landing site. Degraded visual environments were simulated with night vision goggles (NVG) and an unaided night scene. ${ }^{13}$ The OTW scene shown through NVGs includes a variety of visual cueing targets as shown in Fig. 4.

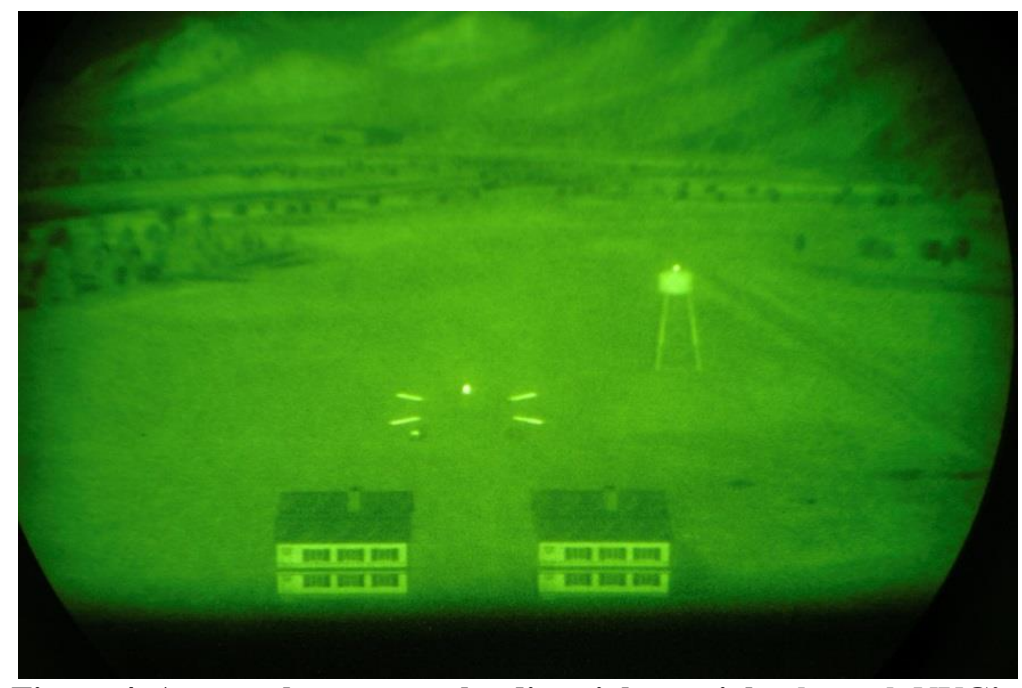

Figure 4. Approach to remote landing sight at night through NVG's.

\section{Sample Tranfer of Training Tasks}

1) In 2014 a NASA transfer-of-training study was performed in the VMS. The purpose of the study was to investigate the effect of false tilt cues on training and transfer of training of manual roll control skills. Of specific interest were the skills needed to control unstable roll dynamics of a mid-size transport aircraft close to the stall point. The pilots' task was to actively minimize the roll error presented on a compensatory display, which resembled a basic Primary Flight Display (PFD) (See Fig. 5). The test variations included three different levels of motion: no motion, roll motion only, and coordinated roll motion. ${ }^{14}$

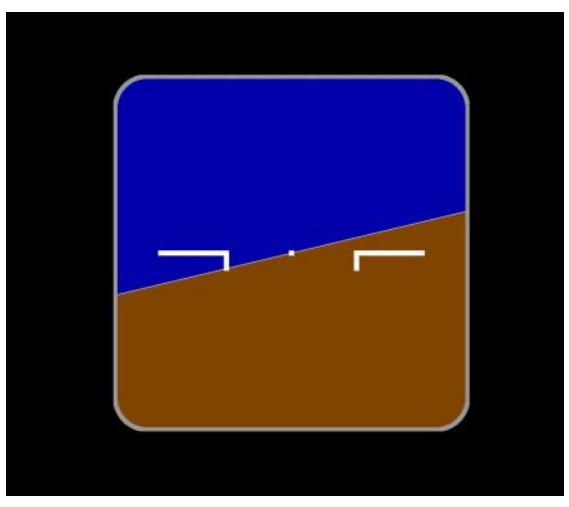

Figure 5. Simplified Primary Flight Display.

2) In 2015 a quasi-transfer-of-training study was performed for the FAA using four challenging commercial transport tasks: approach and landing with sidestep, high altitude stall recovery, overbank upset recovery, and engine out on takeoff. Each task was performed using one of four different motion conditions: no motion, small hexapod, large hexapod, and full VMS motion. The purpose of the experiment was to evaluate whether or not training with motion is valuable for initial training of commercial pilots. ${ }^{15}$ 


\section{Unique Scenario Elements}

The execution of any simulation requires a clearly-defined scenario. A simulation scenario can be defined as the specification of initial and terminal conditions, significant events and the environment as well as the major entities, their capabilities, behavior and interactions over time. ${ }^{5,16}$ There are many elements in a simulation scenario that are common to all flight simulators such as time-of-day, turbulence, wind and visibility. Depending on the the purpose of the flight simulator there can be unique elements that are specific to the simulator.

The wide variety of simulated vehicles and research topics necessitates a system with which changes can be made quickly, easily and repeatable. The VMS Real-Time Environment was developed to support this rapid development capability and provide users effective tools for development, testing and experiment execution. This system provides an integrated debugger, a window to monitor variables and simulation execution, and the ability to deposit values into any variable manually or by loading script files. Special runtime configurable script files are used to set math model variables such as vehicle initial conditions, control system gains, loader force characteristics and test matrix flags. Other script files are also used to define the I/O lists used to send and receive data between the host and all the other devices such as the cab hardware, head down displays and motion system. This system enables fast, easy and repeatable changes to any simulation condition or component while running, without the need to suspend, re-compile or relink any code. While development of scenarios is accomplished using the debugging and the monitoring capabilities, ultimately, the final scenarios are saved and configured primarily using these script files.

R\&D flight simulators are most commonly used to learn about the combined pilot-vehicle interactions using flight scenarios that focus on specific areas of interest. Development of scenarios at the VMS is typically done for each experiment and includes creating each component - the visual cueing targets and conditions, the control system logic, the guidance drive laws, the control force characteristics and the motion drive parameters - and then merging them together and testing the total system's performance. The following sections highlight some of the unique scenario elements that may be common to a research and development simulator such as the Vertical Motion Simulator (VMS).

\section{A. Special OTW Targets and Conditions}

The outside visual scene is provided by a Rockwell Collins eight channel EPX 5000 image generator which can simulate any place on Earth. A high fidelity inset that includes the relevant characteristics of a specific geographical location is developed for the particular area of interest. Numerous airports and other landing sites around the world have been simulated at the VMS. In addition, three-dimensional moving and/or stationary objects can be created and used ascritical scenario components or to enhance the visual cueing environment. For example, a vehicle visual model can be driven dynamically, either via programming or by playing back recorded data, and used as a chase plane. Similarly, a ship visual model can be driven using sea state data and used for shipboard landings. Stationary objects such as PAPIs and cone arrangements can be used to aid task performance, while other models such as buildings or trees can be used to augment the general visual cueing.

As an example, the VMS is used by the US Army to test the handling qualities (HQ) of rotorcraft as specified in ADS-33 standard document. ${ }^{11}$ A selection of flight test maneuvers are specified in the form of precisely defined Mission-Task-Elements (MTEs). These MTEs provide a basis for an overall assessment of the rotorcraft's ability to perform certain critical tasks, and result in an assigned level of HQ. Many of the MTEs require specific OTW targets such as hover boards that must be precisely modeled and located per the ADS-33 specification such that performance by the test subjects can be measured (see

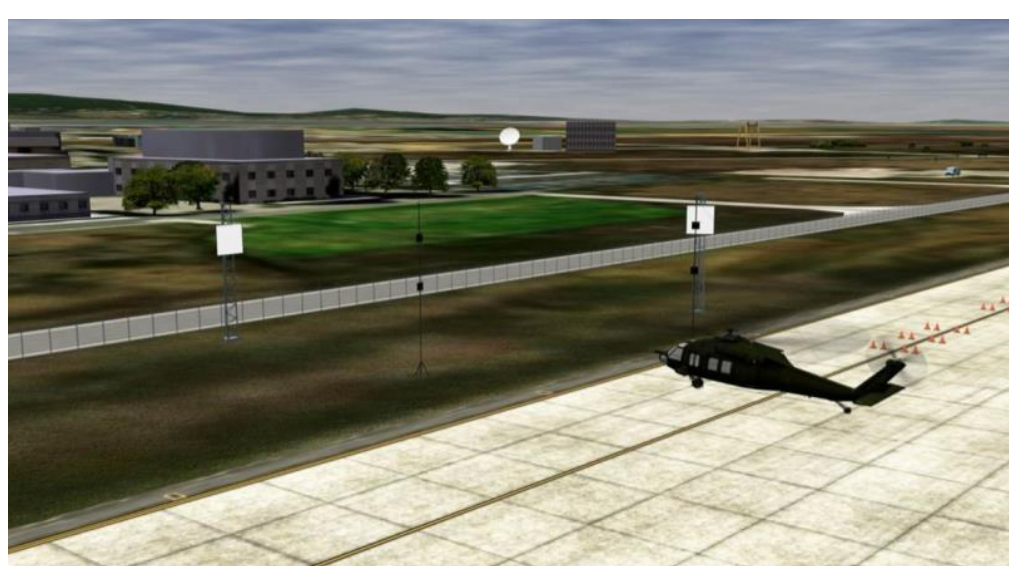

Figure 6. Laboratory view of a modified ADS-33 Vertical Fig. 6).

American Institute of Aeronautics and Astronautics 
Fog and cloud layers are often important aspects of the scenario's visual scene and are frequent components in the experiment test matrix. Lights, such as airport lighting or illumination from vehicles, can also be included in the database and tuned for daytime, unaided nighttime or nighttime with night vision goggles.

In general, the OTW visual scene for each scenario is setup using script files. A local frame is defined such that the latitude and longitude of the primary runway threshold determine the datum, the runway heading, and the orientation. All the moving model targets in the visual scene are then positioned with respect to this local runway frame. OTW script files are used to establish the location of the local frame, which can change from one scenario to the next during the same experiment. The position and scale of the moving model targets, the position and intensity of any lights, as well as flags to enable or disable the targets and lights are also included in these script files. The visibility, time of day, ambient light level, and altitudes of cloud layers are all visual scene parameters that are included in the scenario script files.

\section{B. Motion Drive Parameters}

Unlike most training simulators, the VMS motion system is adjusted for each simulation task by selecting the motion cueing filter gains and washout frequencies that provide the most realistic motion cueing within the simulator motion envelope. The motion tuning is a subjective process where the project pilot flies the maneuver and evaluates the motion cueing. A motion-tuning expert then adjusts the filter motion gains and washouts to satisfy the pilot while staying within the operational motion envelope. ${ }^{17}$

The simulator motion cueing algorithms use high-pass (washout) filters and a rotational/translational cross-feed arrangement shown schematically in Fig. 7. The computed pilot station accelerations, calculated from the vehicle model specific forces, are second-order high-pass filtered, and attenuated, before commanding the motion drive system. The high-pass filter is shown in Eq. 1 where $\mathrm{K}$ is the motion gain, $\omega_{\mathrm{n}}$ is the washout frequency and $\zeta$ is the damping ratio.

$$
\frac{\text { Motion Drive System }}{\text { Pilot Station Acceleration }}=\frac{K \cdot S^{2}}{S^{2}+2 \zeta S+\cdot \omega_{n}^{2}} \quad \text { Equation } 1
$$

Turn coordination, which adds translational acceleration to produce a coordinated turn, and compensation for the rotational center of the simulator account for the cross-coupled motion commands and provide the correct cues at the pilot's station. A low-pass filter tilts the simulator to provide steady-state longitudinal and lateral acceleration cueing at low frequency.

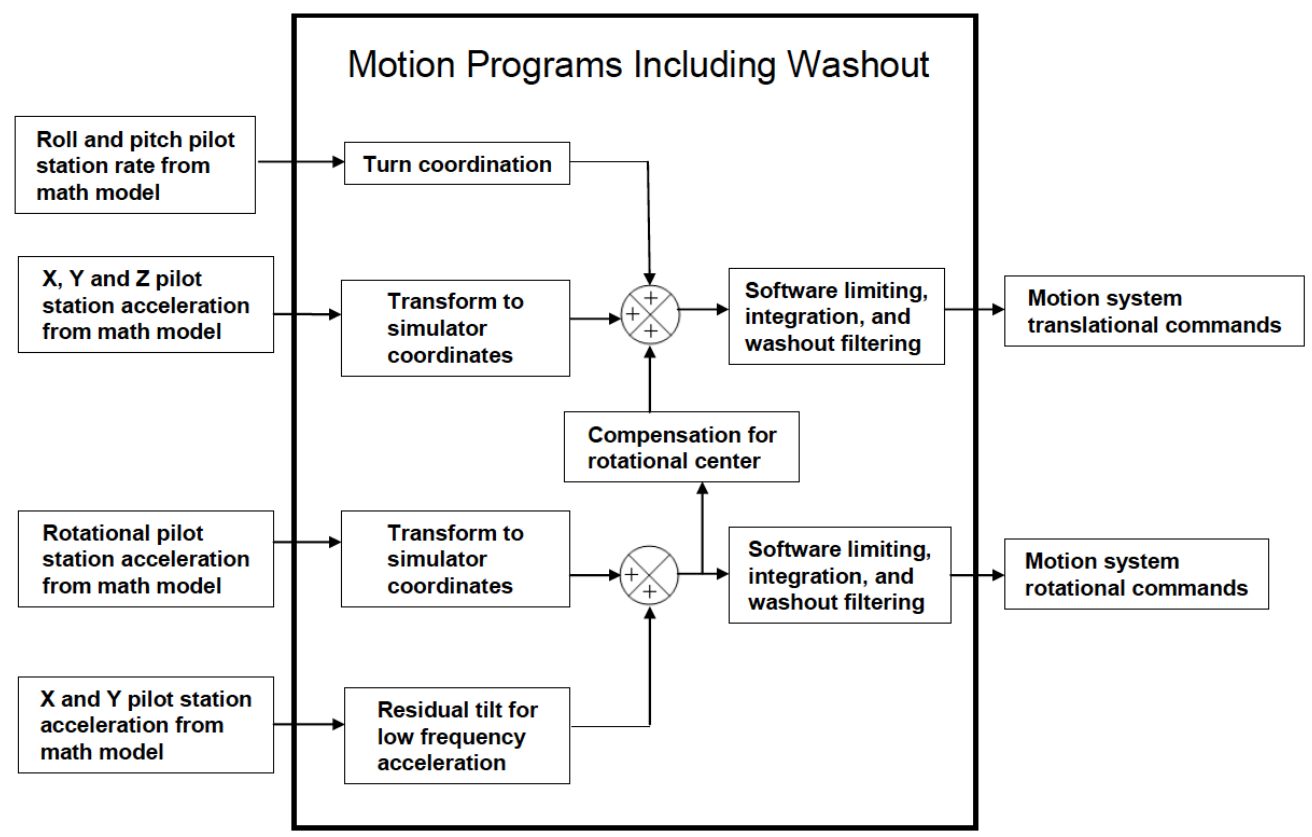

Figure 7. VMS motion algorithm schematic. 


\section{Active Inceptor Parameters}

As a research platform, the VMS must be capable of rapidly simulating both current and proposed pilot control loader (PCL) feedback cues. The McFadden PCL system at the VMS is highly configurable, where the tactile feedback characteristics can be altered in real-time through either the host computer or the McFadden virtual instrument panel. Altering the PCL's in real-time provide the capability for dynamic gradient profiles to be defined. See Appendix A for a complete list of tunable PCL parameters.

The PCL system defines each axis gradient profile through eleven discrete points, an initial gradient with five positive and five negative gradients, then linear approximation is used to define the end to end profile. For dynamic profiles the external force parameter allows for an additional force to be applied and varied in real-time. The most recent use of the external force parameter was utilized to investigate loss of control prediction algorithms on transport aircraft which enabled dynamic tactile feedback cues to the pilot, defining the safe operating envelope of the inceptor. ${ }^{18}$ The McFadden PCL system can provide gradients up to $300 \mathrm{lbs} / \mathrm{in}$ and independent parameters define friction and stiction of an inceptor. ${ }^{19}$

\section{Math Model Parameters}

As a R\&D simulation facility, the VMS supports real-time, piloted ground-based simulations using a system designed to provide a flexible and rapid development environment. A wide variety of vehicles and research topics have been studied at the VMS over the years. The math models, including the vehicle and control system models, which may be developed at the VMS or by visiting researchers, can be in the form of algorithm descriptions, sets of equations or block diagrams, which are either programmed or auto-coded and tested by VMS engineers. The vehicle and control system specific software is integrated with the VMS libraries to create the simulation executable. The simulation software is programmed such that any scenario variation in the test matrix may be selected or initiated by either a flag or gain value. By organizing the simulation in this way, all scenarios can be configured using script files.

Experiment production is accomplished as follows. The simulation executable is brought up on the host computer. The vehicle model is trimmed, which means that control positions are found for the given vehicle state which result in a zero-acceleration steady state. Then the vehicle model will remain frozen in this trimmed, Initial Condition (IC) state, held in place by skipping the dynamics integrations for as long as desired. When the run is initiated, the equation of motion integrations begin and time moves forward. The pilot will then fly the maneuver as instructed and after the run is complete, the simulation will go back to IC.

The scenario configuration changes are made at the host terminal while in IC either by bringing in script files or by typing parameters in by hand. The math model scenario parameters include:

- Initial Condition (IC) States (the vehicle position with respect to the runway threshold, altitude, attitude, airspeed, glideslope) which are numbers with engineering units usually set using a script file.

- Flight Profiles (the test maneuver such as offset approach, formation flight, straight-in w/flare, hover in turbulence, pitch/roll tracking) which includes flags and parameters that enable or disable and set up the OTW and HDD options.

- Vehicle configurations (control system modes, control system gains, guidance options, select advanced technology) which are often determined by setting flags to pre-determined values.

\section{Conclusion}

The purpose of this paper is to highlight some of the unique tasks and scenario elements used at the VMS so they may be captured by scenario standardization efforts initiated by the AIAA Modeling and Simulation Technical Committee.

To support a variety of studies at a research and development simulator such as VMS, four common scenario elements have been identified, which include:

1) Special OTW Targets and Conditions - To define the computer generated images' objects, dimensions, special effects, and coordinates.

2) Motion Drive Paramenters - To set up the motion cueing fidelity with respect to the available motion travel envolope.

3) Active Inceptors Parameters - To produce the force feel characteristics required by the study.

4) Math Model Parameters - To define the vehicle intial flight condition, dynamics, and flight profiles. 


\section{Appendix A}

\begin{tabular}{|c|c|}
\hline Force Limit & $\begin{array}{l}\text { The upper force limit on the Force Command to the Mc- } \\
\text { Fadden analog controller. }\end{array}$ \\
\hline Damping & $\begin{array}{l}\text { Damping factor necessary to counter natural damping in } \\
\text { the pilot control }\end{array}$ \\
\hline Force Breakout & Force required to move control from center. \\
\hline Force Breakout Gradient & $\begin{array}{l}\text { Force gradient for force breakout with an upper limit of } \\
300 \mathrm{lbs} / \mathrm{in} \text {. Force breakout occurs at the posiiton trim } \\
\text { location }\end{array}$ \\
\hline Friction & $\begin{array}{l}\text { The force required to keep moving the pilot control } \\
\text { regardless of velocity position. Also referred to as } \\
\text { hysteresis. Friction force applies outside of deadzone. } \\
\text { of velocity or position. This is also referred to as }\end{array}$ \\
\hline Stiction & $\begin{array}{l}\text { Force required to move control independent of control } \\
\text { position. Applies independent of friction and outside of } \\
\text { deadzone }\end{array}$ \\
\hline Deadzone & Deadband \\
\hline Deadzone Friction & Friction within deadband \\
\hline Deadzone Stiction & Stiction within deadband and independent of friction \\
\hline Position + Stop & Positive stop location \\
\hline Position - Stop & Negative stop location \\
\hline Position Stop Gradient & Position stop force gradient \\
\hline Position Trim & Centering position for pilot control \\
\hline External Force & Force equivalent to pilot force input \\
\hline 11-Segment Force Gradient & $\begin{array}{l}\text { A non-linear piece-wise approximation force gradient } \\
\text { that uses } 5 \text { segments each in the plus and minus } \\
\text { directions. An initial gradient is used for linear gradient } \\
\text { applications. }\end{array}$ \\
\hline Force Scaling & A force scale factor that can be set from 5 to $20 \mathrm{lbs} /$ volt \\
\hline Velocity Scaling & A force scale factor that can be set from 5 to $20 \mathrm{lbs} /$ volt \\
\hline Position Scaling & $\begin{array}{l}\text { A position scale factor that can be set from } 1 \text { to } 2 \\
\text { in/volt }\end{array}$ \\
\hline Control Arm Length & Length from inceptor pivot point to pilot contact point \\
\hline g Compensation & $\begin{array}{l}\text { A force term used to scale the g compensation circuit } \\
\text { for gravity nulling }\end{array}$ \\
\hline Non-Linear Damping & $\begin{array}{l}\text { A damping term used only in the non-linear circuits. } \\
\text { This would be equivalent to the "tach cross-over" that } \\
\text { is found in the McFadden analog controllers. This } \\
\text { setting, when used, can remove the McFadden } \\
\text { tachometer cross-over circuit }\end{array}$ \\
\hline
\end{tabular}

\section{References}

${ }^{1}$ Jackson, E. B., Hildreth, B. L., York, B. W., and Cleveland, W. B., "Evaluation of a Candidate Flight Dynamics Model Simulation Standard Exchange Format," AIAA Modeling and Simualation Technologies Conference and Exhibit, AIAA 2004-5038, Providence, Rhode Island, August 16-19, 2004.

${ }^{2}$ American National Standard, "Flight Dynamics Model Exchange Standard," Document ANSI/AIAA S-119-2011, American Institute of Aeronautics and Astronautics, March 2011.

${ }^{3}$ Advani, S.K., and Hosman, R.J.A.W., "Revising Civil Simulator Standards - An Opportunity for Technological Pull," AIAA Modeling and Simulation Technologies Conference and Exhibit, AIAA 2006-6248, Keystone, Colorado, August 21-24, 2006.

American Institute of Aeronautics and Astronautics 
${ }^{4}$ ICAO, Manual of Criteria for the Qualification of Flight Simulation Training Devices, VOL I (A), 3rd Edition, ICAO-9625, 2009.

${ }^{5}$ Jafer, S., Chhaya, B., Durak, U., and Gerlach, T., "Formal Scenario Definition Language for Aviation: Aircraft Landing Case Study," AIAA Modeling and Simulation Technologies Conference, AIAA 2016-3521, Washington, D.C., June 13-17, 2016.

${ }^{6}$ Aponso, B.L., Beard, S.D., Schroeder, J.A., "The NASA Ames Vertical Motion Simulator - A Facility Engineered for Realism,” Royal Aeronautical Society Spring 2009 Flight Simulation Conference, London, UK, June 3-4, 2009.

${ }^{7}$ Beard, S.D., Ringo, L.A., Mader, B., Buchmann, E.H., and Tanita, T., "Space Shuttle Landing and Rollout Training at the Vertical Motion Simulator," AIAA Modeling and Simulation Technologies Conference and Exhibit, AIAA-2008-6541, Honolulu, HI, 18-21 August 2008.

${ }^{8}$ Danek, George L., "Vertical Motion Simulator Familiarization Guide," NASA TM 103923, May 1993.

${ }^{9}$ Beard, S.D., Reardon, S.E., Tobias, E. L., and Aponso, B. L., "Simulation System Fidelity Assessment at the Vertical Motion Simulator," American Helicopter Society 69 ${ }^{\text {th }}$ Annual Forum, AHS-2012-4634, 13-16 Aug. 2012.

${ }^{10}$ Mueller, R. A., "Optimizing the Performance of the Pilot Control Loaders at the NASA Vertical Motion Simulator," AIAA 2008-6349, AIAA Modeling and Simulation Technologies Conference, AIAA 2008-6349, Honolulu, HI, Aug. 2008.

${ }^{11}$ Anon., "Handling Qualities Requirements for Military Rotorcraft," Aeronautical Design Standard-33 (ADS-33E-PRF), US Army Aviation and Missile Command, Mar. 2000.

${ }^{12}$ Aponso, B.L., Tran, D.T., Schroeder, J.A., and Beard, S.D., "Rotorcraft Research at the NASA Vertical Motion Simulator," AIAA Atmospheric Flight Mechanics Conference, AIAA 2008-6056, Chicago, IL, 10-13 Aug. 2009.

${ }^{13}$ Theodore, C.R., Malpica, C.A., Blanken, C.L., Tischler, M.B., Lawrence, B., Lindsey, J.E., and Berger, T., "Effect of Control System Augmentation on Handling Qualities and Task Performance in Good and Degraded Visual Environments," American Helicopter Society 70 th Annual Forum, Montreal, Canada, 20-22 May 2014.

${ }^{14}$ Zaal, P.M.T., Popovici, A., and Zavala, M., "Effects of False Tilt Cues on the Training of Manual Roll Control Skills," AIAA 2015-0655, AIAA Modeling and Simulation Technologies Conference, Kissimmee, FL, 5-9 Jan. 2015.

${ }^{15}$ Zaal, P.M.T., Schroeder, J.A., and Chung, W.W., "Transfer of Training on the Vertical Motion Simulator," Journal of Aircraft, Vol. 52, No. 6, November-December 2015.

${ }^{16}$ US Department of Defense, High Level Architecture Glossary, US DoD, Washington, DC, 1996.

${ }^{17}$ Reardon, S.E., and Beard, S.D., "Evaluation of Motion Tuning Methods on the Vertical Motion Simulator," 71st American Helicopter Society Annual Forum, Virginia Beach, Virginia, May 5-7, 2015.

${ }^{18}$ Krishnakumar, K., Stepanyan, V., Barlow, J., Hardy, G., Dorias, G., Poolla, C., Reardon, S., Soloway, D., "Initial Evaluations of LoC Prediction Algorithms using the NASA Vertical Motion Simulator," AIAA SciTech, National Harbor, AIAA 2014-0265, Maryland, Jan 13-17, 2014.

${ }_{19}$ Mueller, R.A., “A New Pilot Control Loader System for the Vertical Motion Simulator," Applied Dynamics International, NASA Ames Research Center, January 18, 2005.

American Institute of Aeronautics and Astronautics 